\title{
Monopoly, employment and wages
}

\author{
Chung Yi Tse* \\ University of Hong Kong
}

January 10, 2001

\begin{abstract}
This paper shows that monopoly in the capital equipment market results in higher productivity and wages but lower employment relative to the benchmark of competition. The combined effect on workers' welfare is negative for expected earnings, defined as the product of the probability of employment and the wage earned when employed, is lowered. More interestingly, the declines in employment and expected earnings are greater for low skill workers. Increases in the relative supply of high skill workers intensify the declines. The employment and expected earnings of all workers as well as the employment of low skill workers relative to high skill workers are all decreasing in the relative supply of high skill workers.
\end{abstract}

Keywords: monopoly pricing, wages, unemployment, job-matching.

JEL classifications: D42, E24, J60, L10

${ }^{*}$ Correspondence: School of Economics and Finance, University of Hong Kong, Pokfulam Road, Hong Kong. email: tsechung@econ.hku.hk. tel: +852-2859-1035. fax: 2548-1152. I owe thanks to Riku Kinnunen and Pasi Holm for detailed comments on a previous draft of the paper and two referees for pointing out various important omissions in addition to some very useful suggestions. Financial support from a HKU CRGC grant is gratefully acknowledged. 


\section{INTRODUCTION}

How product market competition affects productivity, wages and employment is an important question. It bears on how much of the deteriorating employment prospect of low skill workers in many developed countries in recent years can be attributed to the increased competition from low wage countries. In turn, opposition against market liberalization has often arisen out of the perceived threat to the employment of workers in the protected sectors. This view is not without merit. In the monopoly rent sharing models surveyed in Nickell (1999), workers do earn higher wages in firms that possess greater market power. And so any market liberalizations that erode the market power of the firms can certainly lower wages.

There are other dimensions to the effects of product market competition on labour market outcomes. This paper contributes to the debate by exploring a channel in which product market competition instead benefits workers in general and low skill workers in particular. The analysis borrows heavily from the celebrated Mussa and Rosen (1978) monopoly pricing model. In the Mussa and Rosen model, buyers are differentiated by their intensities of preference for the quality of the good. All buyer types are made worse off in monopoly in comparison to competition. But it is the low demand buyers that are particularly shortchanged by market power. Increased competition should thus benefit low demand buyers more than high demand buyers. The model can be easily adapted to study to the effects of market power on the labour market by taking the buyers as firms with job vacancies to fill and the good as capital equipment. Assuming physical and human capital complementarity, firms employing high skill workers are high demand buyers that are willing to pay more for more productive capital equipment. The insights from the Mussa and Rosen model immediately suggest that market power will make workers of all skill levels worse off and more so for low skill workers. 
The analysis of employment in this paper is based on the job-matching model introduced by Pissarides (1990) and Diamond and Blanchard (1989) in which the matching of workers and job vacancies is governed by a constant returns to scale and concave job matching function. To the standard model, I add the analysis of monopoly pricing in the market for capital equipment and compare the productivity, employment and wages of high and low skill workers to a benchmark of perfect competition in the capital equipment market.

Not unexpectedly, monopoly pricing in the input market, by virtue of extracting greater surplus from firms in the downstream industry, lowers the employment of workers of all skill levels. The effects on productivity and wages are less obvious. As fewer jobs are created, the labour markets become less tight and so the vacancies are filled with higher probabilities. As a result, firms will find it optimal to invest in more productive equipment for the equipment will be employed more often. Higher wages then follow from the increased productivity of the job matches. Even though the jobs offered are better jobs, workers are made worse off in comparison to the competitive benchmark. That is the case as the expected earnings, defined as the product of the probability of employment and the wage earned when employed, are lowered.

Are firms hiring high skill workers necessarily willing to pay more for more productive equipment given the assumed physical-human capital complementarity and so a perfectly discriminating monopolist will find it optimal to offer them more productive equipment at a higher price? The answer is no. In a job-matching model, there is no unambiguous ranking among firms hiring workers of different skill levels in terms of the willingness to pay for more productive equipment. The assumed physical-human capital complementarity certainly tends to cause firms hiring high skill workers willing to pay more. But the willingness to pay also depends on the probability that the job vacancies are filled which in turn depends on the monopolist's pricing policy. In some special case, a perfectly discriminating monopolist will find it optimal not to 
discriminate among firms hiring workers of different skill levels, but to offer the same piece of equipment for sale to all firms at identical prices. In general, a perfectly discriminating monopolist does find it optimal to adopt a pricing policy that would make firms in the high skill market willing to pay more for more productive equipment and discriminate firms in the two markets by selling more productive equipment to the high skill market at a higher price.

Perfect price discrimination is seldom feasible in practice. Absent the ability to differentiate firms offering jobs to workers of different skill levels, the monopolist will have to rely on firms self-selecting themselves into the appropriate markets. To do so, the price-productivity pairs offered in the different markets have to obey some incentive compatibility constraints that ensure that firms hiring workers of one skill type indeed find it optimal to invest in the equipment targeted at the market concerned. It turns out that a monopolist restricted to second degree price discrimination will choose not to discriminate altogether, but to sell the same piece of equipment to all firms at identical prices, just as in those special cases of perfect price discrimination.

The quality of the equipment to be offered for sale in this case is a compromise of the two distinct qualities in perfect price discrimination. Specifically, firms hiring low skill workers will be forced to invest in more productive and more costly equipment than otherwise whereas firms in the high skill market may now enjoy the benefit of investing in less costly equipment. The expected return on job creation in the low skill market is forced down further below while the expected return in the high skill market rises above the respective expected returns in perfect price discrimination. Hence low skill workers are made worse off relatively more than high skill workers in second degree price discrimination.

In response to an increase in the relative supply of high skill workers, the monopolist will find it optimal to raise the quality and price of the single piece of equipment offered for sale. This lowers the expected returns on job creation in both markets. 
In equilibrium, job creation for both skill types go down. ${ }^{1}$ Furthermore, the decline is greater in the low skill market. Hence as more of the population acquires skills, low skill unemployment will go up both absolutely and relatively. Similar results are established in Saint-Paul (1996) and Acemoglu (1997). These studies model the idea that the hiring of a low skill worker involves the forgone opportunity of recruiting a high skill worker for the job vacancy. When the supply of high skill workers become more abundant, firms are increasingly unwilling to fill job vacancies with low skill workers. In these models, the fortunes of high and low skill workers resemble a zerosum game, with more jobs for one skill type at the expense of less jobs for the other. In contrast, an increase in the relative supply of high skill workers in the present model will cause the employment of both skill types to go down. Nevertheless, as the decline is greater for low skill workers, the prediction is similar to those of Saint-Paul (1996) and Acemoglu (1997).

The next section presents the model. In section 3, I solve the model with a competitive market for capital equipment to set up a benchmark for comparison. The effects of monopoly are examined in section 4. Section 5 discusses the efficiencies of the various market structures considered in the paper. Section 6 provides some brief concluding remarks.

\section{MODEL}

\section{A. Environment}

The output market is perfectly competitive and the demand is perfectly elastic at a unit price of one. ${ }^{2}$ The production is fixed coefficient, with each employed

\footnotetext{
${ }^{1}$ The aggregate employment rate could well go up since there are more workers in the high employment group.

${ }^{2}$ There is no change in substance under the alternative assumption that there is a downward sloping demand curve. For the welfare effects of monopoly pricing in an upstream industry selling
} 
worker equipped with one machine and where machine qualities and worker skills are complements. Specifically, the output produced by a worker with skill level $h$ matched to a machine of quality $q$, which $\operatorname{costs} c(q)=q^{\gamma}$ for some $\gamma>1$ to produce, ${ }^{3}$ is given by

$$
y=h q .
$$

There are two periods $t=0$ and 1 . In $t=0$, a firm may create a job vacancy by investing a fixed sum equal to $c$. In $t=1$, job matches are formed among firms that have previously posted vacancies and workers searching for jobs. There are two skill levels: high skill $h_{H}$ and low skill $h_{L}$, where $h_{H}>h_{L}$ and two spatially separated labour markets, one for each skill type. I rule out cross-market searches by assuming that firms posting vacancies in the market for high skill workers can make a credible threat not to hire any low skill workers that happen to show up. ${ }^{4}$

The matching of vacancies and workers is governed by the Diamond-MortensenPissarides job matching function $m\left(v_{s}, n_{s}\right)$ which yields the number of successful job matches in the market for $s=H$ or $L$ workers as a function of the number of vacancies $v_{s}$ posted and the number of workers searching for jobs in the market, which I assume to be fixed at some $n_{s}$. Under the usual assumption that the job matching function exhibits constant returns to scale, the probability that a type $s$ worker is successfully matched with a job is $\mu\left(\theta_{s}\right)=m\left(\theta_{s}, 1\right)$ where $\theta_{s}=v_{s} / n_{s}$ is the tightness of the labour to a competitive downstream industry facing a downward sloping demand curve, see Ordover and Panzar (1982).

${ }^{3}$ It may appear odd that machine production exhibits constant returns in quantity but decreasing returns in quality. With the state of knowledge fixed at a given point in time, it is probably not unreasonable that it would be progressively more costly to produce more productive equipment. If the industry is small relative to the entire economy, the constant returns in quantity assumption is not inappropriate.

${ }^{4}$ Similar assumptions are made in Saint-Paul (1996) and Mortensen and Pissarides (1999) where they rule out cross-market searches by assuming that low skill workers are completely unproductive in jobs designed for high skill workers. 
market for type $s$ workers. The probability that a vacancy posted for type $s$ workers is filled is $\eta\left(\theta_{s}\right)=m\left(1, \theta_{s}^{-1}\right)=\mu\left(\theta_{s}\right) / \theta_{s}$. Assuming that the matching function is increasing in both arguments, the workers' employment probability $\mu$ is increasing while the firms' recruiting probability $\eta$ is decreasing in $\theta$.

\section{B. Timing of events}

Investment in physical capital by firms is irreversible, and will have to be made before job matches are formed. ${ }^{5}$ The assumption is arguably the more empirically relevant assumption than the alternative that investment may be made after the vacancies are filled. It turns out that the timing assumption is not crucial as the more important results of the paper survive the change in the timing assumption under some appropriate conditions. ${ }^{6}$ (To the referee: the analysis with the alternative timing assumption is in appendix B at the end of the paper) Now with investment sunk before job matches are formed, the appropriable surplus created by a job match is simply the match's gross output as specified in (1) which I assume to be shared by the firm and the worker in fixed proportion via Nash bargaining, with $\beta<1$ the worker's share and $1-\beta$ the firm's share. To summarize, the timing of events is as follows:

(i) In $t=0$, firms post vacancies by paying the fixed cost of job creation $c$ and the cost of physical capital investment $p(q)$ that depends on the qualities of the machines that they purchase,

(ii) In $t=1$, the matching of vacancies and workers takes place as governed by $m\left(v_{s}, n_{s}\right)$,

(iii) production then commences and the parties share the appropriable surplus $y=h q$

\footnotetext{
${ }^{5}$ Investment can be reversible only if there is a second hand market for machines, which is not consistent with the premise of this paper that machine producers may possess market power.

${ }^{6}$ The analysis under the alternative timing assumption is in an appendix available upon request.
} 
in fixed proportion.

The expected return on job creation for $s=H$ or $L$ workers is thus equal to

$$
R_{s}\left(\theta_{s}\right)=\max _{q}\left\{\eta\left(\theta_{s}\right)(1-\beta) h_{s} q-p(q)-c\right\}
$$

There is free entry in job creation. Hence in the absence of non-price rationing in the market for machines, job creation will proceed until $R_{s}\left(\theta_{s}\right)=0$.

\section{COMPETITIVE BENCHMARK}

To isolate the effects of monopoly in capital equipment on employment and wages, I shall first close the model assuming that the market for machines is competitive to set up a benchmark for comparison. If the market for capital equipment is competitive, the supply of machines of quality $q$ will be perfectly elastic at the price $p(q)=q^{\gamma}$ that is equal to the unit cost of production. Taking first order condition of (2) yields

$$
q_{s}=\left(\frac{\eta\left(\theta_{s}\right) h_{s}(1-\beta)}{\gamma}\right)^{\frac{1}{\gamma-1}}
$$

For a given probability that a vacancy will be filled, firms will invest in higher quality machines for higher skill workers due to the physical and human capital complementarity. And for a given skill level, firms will invest in higher quality machines if vacancies are more likely to be filled. Although both the output market and the market for machines are competitive, the investment choice is not generally efficient. For there is the usual under-investment in physical capital that results from the holdup problem in bargaining models of wage determination. Efficiency in physical capital investment is attained only if firms may appropriate the entire match surplus, i.e. when $\beta=0$.

Substituting (3) into (2), we have under free entry in job creation

$$
\left(\frac{\eta\left(\theta_{s}\right) h_{s}(1-\beta)}{\gamma}\right)^{\frac{\gamma}{\gamma-1}}(\gamma-1)=c .
$$


The left side is the firm's expected net revenue. So long as it exceeds the fixed cost of job creation, more vacancies will be posted, raising $\theta_{s}$ and driving down $\eta\left(\theta_{s}\right)$ in the process. ${ }^{7}$ The condition implies that $\eta\left(\theta_{s}\right)$ is decreasing in $h_{s}$, meaning that more vacancies will be created in equilibrium for higher skill workers. This should be the case since if the higher skill workers help firms earn a greater profit, the zero expected return condition is only met when each vacancy is filled with a lower probability via greater job creation.

With skill-machine quality complementarity, does it necessarily follow that firms will invest in higher quality equipment for higher skill workers? Interestingly, the answer is no. In particular, (4) implies that $\eta\left(\theta_{s}\right) h_{s}$ is independent of $h_{s}$ and from $(3), q_{s}$ is therefore independent of $h_{s}$. In other words, high and low skill workers will be equipped with machines of the same quality in equilibrium. The assumed skill-quality complementarity certainly tends to cause machine qualities to increase with skills. There is, however, an indirect and negative effect that works through the probability that vacancies are filled. If the vacancies created for higher skill workers will only be filled with a lower probability because of the more intense competition for workers, by (3) firms find it optimal to invest in lower quality machines. In general, the overall effect can be either positive or negative. Under the multiplicative specification adopted for the production function in (1), the two effects however exactly cancel

\footnotetext{
${ }^{7}$ To ensure that a positive number of jobs are created, the left side of (4) has to exceed $c$ so that the equation may only be solved by some $\eta\left(\theta_{s}\right)<1$. Otherwise, the firm can not recover the fixed cost of job creation even when the vacancy will be filled with certainty in which case no jobs will be created in equilibrium.
} 
out, leaving neither a positive nor negative effect of skill levels on machine qualities. ${ }^{8}$ I focus on this case as the multiplicative specification offers considerable simplification of the analysis and eases the comparison with the monopoly pricing literature in which the multiplicative specification is standard.

With $h_{H}>h_{L}$, a direct corollary of (4) is that $\theta_{H}>\theta_{L}$ in equilibrium. The practical importance is that high skill workers should enjoy a higher rate of employment. There is a long line of inquiry including the early work of Akerlof (1969) and more recent investigations like Machin and Manning (1997) that has adopted similar arguments as explanations for why low skill workers suffer higher unemployment. This conclusion, however, is subject to the qualification that it is not too expensive to create jobs for high skill workers relative to low skill workers. If the fixed costs of job creation for the two types of workers $c_{H}$ and $c_{L}$ are not identical as assumed above but instead $c_{H}>c_{L}$. Then $\theta_{H}$ may not exceed $\theta_{L}$ even if $h_{H}>h_{L}$. We have from (4) again

$$
\frac{\eta\left(\theta_{H}\right)}{\eta\left(\theta_{L}\right)}=\left(\frac{c_{H}}{c_{L}}\right)^{\frac{\gamma-1}{\gamma}} \frac{h_{L}}{h_{H}}
$$

from which it follows that $\eta\left(\theta_{H}\right) / \eta\left(\theta_{L}\right)<1$ only if $\left(c_{H} / c_{L}\right)^{\frac{\gamma-1}{\gamma}}<h_{H} / h_{L}$. That is the productivity differential has to exceed the cost differential sufficiently for the theory to predict higher unemployment for low skill workers. Although not an implausible assumption, this restriction does render the prediction less robust. To foretell what follows, higher unemployment for low skill workers does become a more robust prediction of theory under monopoly in capital equipment.

\footnotetext{
${ }^{8}$ In general, for any production function $f(h, q)$, it can be shown that$$
\operatorname{sign}\left(\frac{d q}{d h}\right)=\operatorname{sign}\left(f(h, q) \frac{\partial^{2} f(h, q)}{\partial h \partial q}-\frac{\partial f(h, q)}{\partial h} \frac{\partial f(h, q)}{\partial q}\right)
$$

which may be either positive or negative. For example suppose output is CES in skill and machine quality $f(h, q)=\left(h^{\lambda}+q^{\lambda}\right)^{\frac{1}{\lambda}}$. Then $d q / d h \geq 0$ if and only if $\lambda<0$. This explains why with a simple multiplicative specification $f(h, q)=h q$, workers of any skill levels will be equipped with machines of the same quality as $d q / d h=0$ in this case.
} 
The competitive benchmark is not efficient. ${ }^{9}$ First there is the under-investment in physical capital due to the hold-up problem as noted previously. The fixed cost of job creation is subject to the same hold-up problem for it is also sunk before job matches are formed, which tends to cause suboptimal job creation. There is an opposing distortion that is the negative externality a firm imposes on others when posting a job vacancy. The negative externality arises out of the fact that the creation of an additional vacancy lowers the probability that other vacancies are filled, which tends to cause excessive job creation in equilibrium. ${ }^{10}$ Under monopoly in equipment, there is a fourth distortion from monopoly pricing. The comparison between monopoly and competition to follow serves to highlight the effects of this distortion on productivity, employment and wages. A full-fledge analysis of the efficiencies of the various market structures is postponed to section 5 .

\section{MONOPOLY IN CAPITAL EQUIPMENT}

\section{A. The participation constraint}

A firm that monopolizes the production of capital equipment obviously no longer has to sell at unit $\operatorname{cost} p(q)=q^{\gamma}$ but may instead pick the price schedule $p(q)$ to maximize profit. The number of machines the monopolist will sell is equal to the number of job vacancies posted in the downstream competitive industry since capital investment is made at the moment job vacancies are posted. The profit the

\footnotetext{
${ }^{9}$ Perhaps it should not be called a competitive benchmark because the labour markets are not Walrasian. It is a competitive benchmark relative to the case where the market for machines is monopolistic.

${ }^{10}$ Hosios (1990) explains that for any concave matching function, there exists some sharing rule $(\beta, 1-\beta)$ under which the two distortions just cancel out, restoring constrained efficiency. Constrained efficiency is generally not attainable when physical capital investment is subject to the hold-up problem as well in a bargaining model of wage determination.
} 
monopolist earns from market $s=H$ and $L$ is thus equal to

$$
\pi_{s}=v_{s}\left(p_{s}-q_{s}^{\gamma}\right)
$$

where $p_{s}$ denotes the price charged for machine $q_{s}$ targeted at the market for type $s$ workers. The prices that the monopolist may charge are limited by the participation constraints that leave the competitive downstream firms in either labour market with non-negative expected profits. From (2), for $s=H$ and $L$

$$
p_{s} \leq \eta\left(\theta_{s}\right)(1-\beta) h_{s} q_{s}-c
$$

Fixing the quality $q_{s}$ and the number of machines to sell $v_{s}=n_{s} \theta_{s}$, the constraint defines the maximum price that may be charged. If the constraint holds as an equality, the competitive downstream producers earn exactly zero expected return on job creation. When the constraint holds as a strict inequality in one or both markets, the monopolist is leaving certain demand in the markets concerned unsatisfied and as a result allows the firms that are not rationed positive expected return on job creation. This may be optimal for a monopolist that is unable to perfectly price discriminate between firms in the two markets. Before turning to analyzing the more practical case of second degree price discrimination, I shall first examine the simpler case in which the monopolist is assumed to be able to perfectly sort buyers into the two markets. But first we can show that in either case

Proposition 1 The monopolist will set prices, qualities and quantities such that there will be fewer job vacancies created for both skill types compared to the benchmark of a competitive equipment market. Employment declines as a result. And the vacancies created will be filled at higher probabilities.

Proof. Let $\theta_{s}^{c}$ and $\theta_{s}^{m}$ be respectively the market tightness in competition and monopoly. The monopolist obviously will pick the price, quality and quantity offered 
for sale in each market to earn strictly positive profits for it always has the option to entirely shut down the market concerned. From (5) and (6), this implies

$$
\eta\left(\theta_{s}^{m}\right)(1-\beta) h_{s} q_{s}-q_{s}^{\gamma}>c
$$

in monopoly. If $\eta\left(\theta_{s}^{c}\right) \geq \eta\left(\theta_{s}^{m}\right)$,

$$
c=\max _{q}\left\{\eta\left(\theta_{s}^{c}\right)(1-\beta) h q-q^{\gamma}\right\} \geq \eta\left(\theta_{s}^{m}\right)(1-\beta) h_{s} q_{s}-q_{s}^{\gamma}
$$

for any $q_{s}$, which contradicts $(7)$. We must then have $\eta\left(\theta_{s}^{c}\right)<\eta\left(\theta_{s}^{m}\right)$ and $\theta_{s}^{c}>\theta_{s}^{m}$.

\section{B. The perfectly discriminating monopolist}

The monopolist's total profit from the two markets may be written as

$$
\Pi=n_{H} \theta_{H}\left(p_{H}-q_{H}^{\gamma}\right)+n_{L} \theta_{L}\left(p_{L}-q_{L}^{\gamma}\right) .
$$

With the numbers of workers in the two markets given, the profit maximization is over the qualities $\left(q_{H}, q_{L}\right)$ and the quantities $\left(v_{H}, v_{L}\right)=\left(n_{H} \theta_{H}, n_{L} \theta_{L}\right)$ of machines to offer for sale and the price to charge $\left(p_{H}, p_{L}\right)$ subject to the participation constraints (6) . For each $\left(q_{s}, \theta_{s}\right)$ pair, $s=H$ and $L$, the participation constraints define the maximum prices that may be charged. In the absence of the necessity to be concerned with incentive compatibility in second degree price discrimination, the perfectly discriminating monopolist finds it optimal to charge just the maximum since the profit from either market is increasing in the price charged, other things equal. Substituting the constraints as equalities into (8) yields

$$
\Pi=n_{H} \theta_{H}\left(\eta\left(\theta_{H}\right)(1-\beta) h_{H} q_{H}-c-q_{H}^{\gamma}\right)+n_{L} \theta_{L}\left(\eta\left(\theta_{L}\right)(1-\beta) h_{L} q_{L}-c-q_{L}^{\gamma}\right) .
$$

The participation constraints may be thought of as the inverse demand curves. Fixing the qualities of the machines to offer for sale, the demand curves are downward sloping as increases in the number of machines that may be sold $v_{s}=n_{s} \theta_{s}$ would come at the expense of a lower price given that $\eta$ is a decreasing function. 
Taking first order conditions of (9) with respect to $q_{s}, s=H$ and $L$ yields exactly (3) that applies when the market for machines is competitive. Hence, were the $\eta\left(\theta_{s}\right)$ 's identical across the two market structures, the monopolist would be offering machines of the same quality that are chosen in competition. But the $\eta\left(\theta_{s}\right)$ 's are not identical across the two market structures. In marking up prices above unit production costs, monopoly pricing results in lower job creation in equilibrium, raising the $\eta\left(\theta_{s}\right)$ 's in the process. ${ }^{11}$ Specifically the first order condition of (9) with respect to $\theta_{s}$ is

$$
\left(\eta\left(\theta_{s}\right)(1-\beta) h_{s} q_{s}-c-q_{s}^{\gamma}\right)+\theta_{s} \eta^{\prime}\left(\theta_{s}\right)(1-\beta) h_{s} q_{s}=0
$$

Plugging (3) into the above for $q_{s}$ yields

$$
\left(\frac{(1-\beta) \eta_{s}\left(\theta_{s}\right) h_{s}}{\gamma}\right)^{\frac{\gamma}{\gamma-1}}\left(\gamma\left(1+\varepsilon_{\eta}\left(\theta_{s}\right)\right)-1\right)=c
$$

where $\varepsilon_{\eta}(\theta)=\theta \eta^{\prime}(\theta) / \eta(\theta)<0$ denotes the elasticity of $\eta$ with respect to $\theta$. I should impose the following regularity conditions on the matching function to ensure that the monopolist's profit maximization is well-defined.

\section{Assumption 1:}

(a) $\gamma\left(1+\varepsilon_{\eta}(\theta)\right)-1>0$ for some $\theta$.

(b) $\varepsilon_{\eta}(\theta)$ is non-increasing in $\theta$.

The first part of the assumption is necessary for there to exist some positive $\theta$ that solves (10). The second part, in guaranteeing that the left side of the first order

\footnotetext{
${ }^{11}$ In the Mussa and Rosen (1978) model and much of the literature that follows, a perfectly discriminating monopolist will offer the same quality as under competition but charges a price to extract all the surplus from the buyers. In the present analysis, it is not possible for a perfectly discriminating monopolist to break up the price decision from the quality decision. When the monopolist charges higher prices, the expected returns on job creation decline and the zero profit conditions are restored only when few vacancies are posted, with each vacancy filled with a higher probability. Once this happens, firms would like to invest in higher quality machines as they would be employed more often. And in turn the monopolist would find it optimal to supply higher quality machines as this allows more surplus to be extracted.
} 
condition for maximum is downward sloping, ensures sufficiency. If the matching function is CES, this condition is satisfied if the elasticity of substitution between the two inputs is not greater than unity. Specifically, $\partial \varepsilon_{\eta}(\theta) / \partial \theta \leq 0$ if and only if the elasticity of substitution of the matching function $\sigma \leq 1$.

The first order condition (10) implies that, under assumption $1(\mathrm{~b}), \eta\left(\theta_{s}\right)$ is decreasing in $h_{s}$ and so $\theta_{H}>\theta_{L}$. Hence just as in the competitive benchmark, high skill workers enjoy better employment prospects. While there are fewer jobs created for both skill types compared to competition, the jobs created are better jobs.

Proposition 2 The perfectly discriminating monopolist offers better quality machines for sale in either market, resulting in higher productivity and wages for both skill types. The workers are worse off nevertheless as expected earnings fall below the competitive benchmark.

Proof. Machine qualities are given by the same equation (3) that holds in either competition or perfect price discrimination. Proposition 1 establishes that there would be fewer jobs created in monopoly, i.e. $\theta_{s}^{m}<\theta_{s}^{c}$ and therefore $\eta\left(\theta_{s}^{m}\right)>\eta\left(\theta_{s}^{c}\right)$. The machines offered by the monopolist must then be of higher qualities than the machines chosen in competition. Wages are given by

$$
w_{s}=\beta h_{s} q_{s}
$$

that are increasing in productivity and hence would be higher when firms invest in more productive equipment. Expected earnings are given by

$$
E\left[w_{s}\right]=\mu\left(\theta_{s}\right) \beta h_{s} q_{s}=\theta_{s} \eta_{s}\left(\theta_{s}\right) \beta h_{s} q_{s}
$$

Substituting in (3) for $q_{s}$ yields

$$
E\left[w_{s}\right]=\theta_{s}\left(h_{s} \eta\left(\theta_{s}\right)\right)^{\frac{\gamma}{1-\gamma}}\left(\frac{(1-\beta)}{\gamma}\right)^{\frac{1}{1-\gamma}} \beta
$$


which can be shown to be increasing in $\theta_{s}$ under assumption $1(\mathrm{a})$. The lowering of $\theta_{s}$ in monopoly thus results in falling expected earnings.

In competition, firms posting vacancies for either skill type invest in machines of the same quality in equilibrium. Would the monopolist find it optimal to differentiate the two markets? There is no unambiguous ranking of demand for quality between firms in the two markets in the present model, unlike the standard setup in the monopoly pricing literature in which the markets can be ranked in terms of the demand for quality. Even though the marginal product of machine quality is greater if production is undertaken with high skill workers, firms creating vacancies for these workers do not necessarily have greater demand for quality. For the demand also depends on the probability that the vacancy will be filled. More precisely, the demand for quality is given by the multiple $\eta\left(\theta_{s}\right) h_{s}$ which the monopolist can influence through controlling the quantity in the market concerned. Whether it is optimal for the monopolist to choose a selling strategy to result in $\eta\left(\theta_{H}\right) h_{H}>\eta\left(\theta_{L}\right) h_{L}$ depends on the properties of the matching function.

Proposition 3 If $\varepsilon_{\eta}\left(\theta_{s}\right)$ is constant, the perfectly discriminating monopolist finds it optimal to set $\eta\left(\theta_{H}\right) h_{H}=\eta\left(\theta_{L}\right) h_{L}$ and offer machines of the same quality to the two markets at identical prices. If $\varepsilon_{\eta}\left(\theta_{s}\right)$ is decreasing, the monopolist finds it optimal to set $\eta\left(\theta_{H}\right) h_{H}>\eta\left(\theta_{L}\right) h_{L}$ and offer higher quality machines to the high skill market at a higher price.

Proof. With machine qualities given by (3), we have

$$
\frac{q_{H}}{q_{L}}=\left(\frac{\eta\left(\theta_{H}\right) h_{H}}{\eta\left(\theta_{L}\right) h_{L}}\right)^{\frac{1}{\gamma-1}}=\left(\frac{\gamma\left(1+\varepsilon_{\eta}\left(\theta_{L}\right)\right)-1}{\gamma\left(1+\varepsilon_{\eta}\left(\theta_{H}\right)\right)-1}\right)^{\frac{1}{\gamma}}
$$

where the second inequality obtains after substituting from (10). If $\varepsilon_{\eta}\left(\theta_{s}\right)$ is constant, $q_{H}=q_{L}$. If $\varepsilon_{\eta}\left(\theta_{s}\right)$ is decreasing, $q_{H}>q_{L}$ since $\theta_{H}>\theta_{L}$. Setting the participation 
constraints as equalities and substituting from (3) yields

$$
p_{s}=\left(\frac{\eta\left(\theta_{s}\right) h_{s}(1-\beta)}{\gamma}\right)^{\frac{\gamma}{\gamma-1}} \gamma-c
$$

which is strictly increasing in machine qualities by virtue of (3) again. Hence, if the monopolist finds it optimal to offer the same piece of equipment for sale in either market, it will find it optimal to charge the same price. If it finds it optimal to offer more productive machines for sale in the high skill market, it will charge a higher price for it.

That market power in the market for capital equipment makes workers worse off is perhaps not surprising. The more interesting question is how the two skill types fare relative to each other.

Proposition 4 If $\varepsilon_{\eta}(\theta)$ is constant, perfect price discrimination has no effects on the wage premium $w_{H} / w_{L}$, the relative rate of employment $\mu\left(\theta_{H}\right) / \mu\left(\theta_{L}\right)$ and the ratio of expected earnings $E\left[w_{H}\right] / E\left[w_{L}\right]$ relative to the corresponding levels in competition. If $\varepsilon_{\eta}(\theta)$ is decreasing, the wage premium is inflated while the relative rate of employment and the ratio of expected earnings may rise or fall below the corresponding levels in competition.

Proof. The wage premium is $w_{H} / w_{L}=h_{H} q_{H} / h_{L} q_{L}$ by virtue of $(11)$. If $\varepsilon_{\eta}(\theta)$ is constant, $q_{H}=q_{L}$ in either competition or perfect price discrimination and so the wage premium is left unaffected. If $\varepsilon_{\eta}(\theta)$ is decreasing, $q_{H}>q_{L}$ that will raise the wage premium above the level in competition. The relative rate of employment may be written as

$$
\frac{\mu\left(\theta_{H}\right)}{\mu\left(\theta_{L}\right)}=\frac{\theta_{H} \eta\left(\theta_{H}\right)}{\theta_{L} \eta\left(\theta_{L}\right)}=\frac{\eta^{-1}\left(\frac{\eta_{H}}{\eta_{L}} \eta_{L}\right)}{\eta^{-1}\left(\eta_{L}\right)} \frac{\eta_{H}}{\eta_{L}}
$$

where $\eta^{-1}$ denotes the inverse function of $\eta$ and $\eta_{s}=\eta\left(\theta_{s}\right)$. In competition, $\eta_{H} / \eta_{L}=$ $h_{L} / h_{H}$ by virtue of (4), whereas in perfect price discrimination

$$
\frac{\eta_{H}}{\eta_{L}}=\frac{h_{L}}{h_{H}}\left(\frac{\gamma\left(1+\varepsilon_{\eta}\left(\theta_{L}\right)\right)-1}{\gamma\left(1+\varepsilon_{\eta}\left(\theta_{H}\right)\right)-1}\right)^{\frac{\gamma-1}{\gamma}}
$$


by virtue of (13). If $\varepsilon_{\eta}(\theta)$ is constant, the above reduces to $\eta_{H} / \eta_{L}=h_{L} / h_{H}$ also and fixing $\eta_{H} / \eta_{L}$, (14) is independent of $\eta_{L}$. Then perfect price discrimination has no effects on $\mu\left(\theta_{H}\right) / \mu\left(\theta_{L}\right)$. The ratio of expected earnings is given by

$$
\frac{E\left[w_{H}\right]}{E\left[w_{L}\right]}=\frac{\mu\left(\theta_{H}\right)}{\mu\left(\theta_{L}\right)} \frac{w_{H}}{w_{L}}
$$

If $\varepsilon_{\eta}(\theta)$ is constant, neither the relative rate of employment nor the wage premium is affected by perfect price discrimination and so the same conclusion on the ratio of expected earnings follows.

If $\varepsilon_{\eta}(\theta)$ is decreasing, (15) implies that $\eta_{H} / \eta_{L}$ would exceed $h_{L} / h_{H}$ since $\theta_{L}<\theta_{H}$. The increase in $\eta_{H} / \eta_{L}$ has a negative effect on the relative rate of employment as given by (14) under assumption 1(a). When fewer vacancies are created in monopoly, $\theta_{L}$ is lowered, raising $\eta_{L}$ which would have a positive effect on the relative rate of employment as given by (14) if $\varepsilon_{\eta}(\theta)$ is decreasing. No general conclusion is available as to whether the positive or the negative effect will dominate. The ambiguity carries over to the ratio of expected earnings.

In case $\varepsilon_{\eta}(\theta)$ is constant, perfect price discrimination clearly would not be making one skill type worse off relative to the other. While it is true that the wage premium is inflated in case $\varepsilon_{\eta}(\theta)$ is strictly decreasing, perfect price discrimination similarly has no systematic effects on the welfare of one skill type relative to the other since the effect on the ratio of expected earnings is ambiguous. Unless workers are riskinclined, the possible decline in the relative rate of employment could certainly make high skill workers relatively worse off despite the increase in the wage premium. The general conclusion is then there is no systematic tendency for either skill type to suffer particularly more than the other under perfect price discrimination. This result would be overturned in second degree price discrimination to which we now turn. 


\section{Second degree price discrimination}

We now drop the unrealistic assumption that the monopolist can sort firms posting vacancies for different skill types into distinct markets. Absent the ability to perfectly price discriminate, the monopolist will have to rely on the downstream competitive firms to self-select themselves into the appropriate markets. To do so, the pricequality pairs have to satisfy the incentive compatibility constraints:

$$
\begin{aligned}
\eta\left(\theta_{H}\right)(1-\beta) h_{H} q_{H}-p_{H} & \geq \eta\left(\theta_{H}\right)(1-\beta) h_{H} q_{L}-p_{L} \\
\eta\left(\theta_{L}\right)(1-\beta) h_{L} q_{L}-p_{L} & \geq \eta\left(\theta_{L}\right)(1-\beta) h_{L} q_{H}-p_{H}
\end{aligned}
$$

which would ensure that firms creating vacancies for the particular skill type indeed prefer to invest in the type of machines targeted at the particular market. If $\varepsilon_{\eta}(\theta)$ is constant, the perfectly discriminating monopolist finds it optimal to offer the piece of equipment for sale in either market at identical prices, which clearly involves no incentive compatible problems. In this case, first and second degree price discriminations are equivalent as the monopolist finds it optimal not to price discriminate. The more interesting situation is when the monopolist does find it optimal to differentiate between the two markets in its unconstrained profit maximization. Substituting the participation constraints holding as equalities into (16) and (17) yields respectively

$$
\begin{aligned}
& 0 \geq(1-\beta) q_{L}\left(\eta\left(\theta_{H}\right) h_{H}-\eta\left(\theta_{L}\right) h_{L}\right) \\
& 0 \geq(1-\beta) q_{H}\left(\eta\left(\theta_{L}\right) h_{L}-\eta\left(\theta_{H}\right) h_{H}\right) .
\end{aligned}
$$

In perfect price discrimination, if $\varepsilon_{\eta}(\theta)$ is strictly decreasing, we have from proposition 2: $q_{H}>q_{L}$ and $\eta\left(\theta_{H}\right) h_{H}>\eta\left(\theta_{L}\right) h_{L}$. Hence the price-quality pairs in first degree price discrimination are not incentive compatible for the high skill market.

Results from the monopoly pricing literature suggest that it would be optimal for the monopolist to meet incentive compatibility by leaving some positive surplus to 
high demand buyers which in this case are firms creating vacancies for high skill workers while continuing extracting the maximum surplus from low demand buyers that are firms creating vacancies for low skill workers. The maximization of (8) subject to $(16),(17)$ and the participation constraints in (6) under the assumption that $\varepsilon_{\eta}(\theta)$ is strictly decreasing does yield a solution in which firms posting vacancies for low skill workers would continue earning zero expected surplus, whereas firms posting vacancies for high skill workers are left with a certain positive expected surplus. As expected, we have the solution satisfying $\left(\eta\left(\theta_{H}\right) h_{H}, q_{H}, p_{H}\right)>\left(\eta\left(\theta_{L}\right) h_{L}, q_{L}, p_{L}\right)$. And then the machines offered to the low skill market are of lower quality than the machines chosen in competition whereas the machines offered to the high skill market are of higher quality than the machines chosen in competition. (To the referee: the calculations are in appendix A at the back of the paper.)

Yet this is not the solution of second degree price discrimination in the present model as it is not exactly incentive compatible. Specifically, with free entry in job creation and if firms in the high skill market are left with some positive expected surplus, there would be unmet demand and thus non-price rationing for high quality machines. The rationed firms may then turn to investing in the machines targeted at the low skill market. There would be positive surplus to be earned from doing so since

$$
\eta\left(\theta_{H}\right)(1-\beta) h_{H} q_{L}-p_{L}>\eta\left(\theta_{L}\right)(1-\beta) h_{L} q_{L}-p_{L}=c
$$

if $\eta\left(\theta_{H}\right) h_{H}>\eta\left(\theta_{L}\right) h_{L}$. Now so long as

$$
\eta\left(\theta_{H}\right)(1-\beta) h_{H} q_{L}-p_{L}>c
$$

there would be unsatisfied demand for the machines targeted at the low skill market from firms creating jobs for high skill workers. There can then be no possible mechanisms for the monopolist to supply entirely the rationed demand in the high skill market with the machines target at the low skill market if it is to condition the $\theta_{s}$ 's 
such that $\eta\left(\theta_{H}\right) h_{H}>\eta\left(\theta_{L}\right) h_{L}$. That is the case because the last equality in (20) and

$$
\eta\left(\theta_{H}\right)(1-\beta) h_{H} q_{L}-p_{L}=c
$$

cannot both hold unless $\eta\left(\theta_{H}\right) h_{H}=\eta\left(\theta_{L}\right) h_{L}$. Hence, if it remains optimal to supply at least some of the firms in the high skill market with a more productive machine that would be the case if and only if $\eta\left(\theta_{H}\right) h_{H}>\eta\left(\theta_{L}\right) h_{L}$, there will have to be non-price rationing of the machines targeted at the low skill market as well.

In such a scheme, even firms trying to create vacancies for low skill workers would be rationed. This is because if (21) continues to hold, the demand for the low quality machines from firms planning to hire high skill workers would be infinite. Then not all firms, including firms planning to hire low skill workers, that attempt to invest in the low quality machines would sure to have their demand met. As a result, even the last equality in (20) would turn into a strict inequality. And firms that are not rationed would earn some positive expected surplus.

Most of all, no such schemes would work at all. No downstream competitive firms would invest in the machines targeted at the low skill market to create vacancies for low skill workers if $\eta\left(\theta_{H}\right) h_{H}>\eta\left(\theta_{L}\right) h_{L}$. For in this case, the expected surplus of employing the same machine for creating vacancies for high skill workers stays higher. No job creation will take place in the low skill market then. But if it is not optimal to serve the low skill market, not extracting the maximum surplus from firms in the high skill market cannot be optimal in the first place. In all, leaving some positive expected surplus for firms in the high skill market cannot be an incentive compatible and optimal mechanism. ${ }^{12}$

\footnotetext{
${ }^{12}$ Is it possible to solve the problem by offering a price-quality pair specifically for the rationed buyers in the high skill market? Suppose the monopolist offers three quality-price pairs $\left(q_{H}, p_{H}\right)>$ $\left(q_{R}, p_{R}\right)>\left(q_{L}, p_{L}\right)$. The sale of highest quality machines remains rationed with

$$
\eta\left(\theta_{H}\right)(1-\beta) h_{H} q_{H}-p_{H}>c
$$
}


In ruling out the optimality of allowing firms in the high skill market some positive surplus, the incentive compatibility constraints must take on the forms of (18) and (19). The only possibility for both constraints to be met is that

$$
\eta\left(\theta_{H}\right) h_{H}=\eta\left(\theta_{L}\right) h_{L}
$$

With the participation constraints holding as equalities, the profit function in (8) simplifies to

$$
\begin{aligned}
\Pi= & n_{H} \theta_{H}\left(\eta\left(\theta_{H}\right)(1-\beta) h_{H} q_{H}-c-q_{H}^{\gamma}\right)+ \\
& n_{L} \eta^{-1}\left(\eta\left(\theta_{H}\right) h_{H} / h_{L}\right)\left(\eta\left(\theta_{H}\right)(1-\beta) h_{H} q_{L}-c-q_{L}^{\gamma}\right)
\end{aligned}
$$

after substituting in (22). Not unexpectedly, with $\eta\left(\theta_{H}\right) h_{H}=\eta\left(\theta_{L}\right) h_{L}$, the first order conditions with respect to $q_{H}$ and $q_{L}$ imply that the monopolist finds it optimal not to discriminate between the two markets but to offer for sale the same piece of equipment. In fact, (23) implies that as in perfect price discrimination, $q_{H}\left(=q_{L}\right)$ is given by the same equation (3) that applies in competition.

Proposition 5 If the monopolist may only use price-quality pairs to discriminate between the two markets, the only incentive compatible scheme involves extracting all expected surplus from firms in either market by offering the same piece of equipment to the two markets at the same price.

while

$$
\eta\left(\theta_{H}\right)(1-\beta) h_{H} q_{R}-p_{R}=c
$$

so that the rationed firms' demand would be entirely met by the $\left(q_{R}, p_{R}\right)$ pair. To satisfy incentive compatibility

$$
\eta\left(\theta_{H}\right)(1-\beta) h_{H} q_{R}-p_{R} \geq \eta\left(\theta_{H}\right)(1-\beta) h_{H} q_{L}-p_{L}
$$

But the right side exceeds the right side of $(20)$. Then the $\left(q_{R}, p_{R}\right)$ pair cannot possibly extract all expected surplus from firms in the high skill market. There will have to be rationing in the sale of the $\left(q_{R}, p_{R}\right)$ pair as well and there continues to be unsatisfied demand spilling over to the market for the $\left(q_{L}, p_{L}\right)$ pair. The problem of the low skill market not being served remains unresolved. 
Proof. The first part of the proposition follows from the discussion above. Charging different prices for the same equipment in the two markets is clearly not incentive compatible. The steps that lead to the specification in (23) do however ensure incentive compatibility.

Furthermore, proposition 2 continues to hold in second degree price discrimination.

Proposition 6 In second degree price discrimination, the monopolist will offer better quality machines for sale in either market in comparison to competition, resulting in higher productivity and wages for both skill types. The workers are worse off nevertheless as expected earnings fall below the level in competition.

Proof. Identical to the proof of proposition 2.

What differs from first degree price discrimination is that there are now unambiguous effects on how one skill type fares relative the other in comparison to competition.

Proposition 7 In second degree price discrimination, the wage premium $w_{H} / w_{L}$ remains at the corresponding level in competition. And if $\varepsilon_{\eta}(\theta)$ is strictly decreasing, the relative rate of employment $\mu\left(\theta_{H}\right) / \mu\left(\theta_{L}\right)$ and the ratio of expected earnings $E\left[w_{H}\right] / E\left[w_{L}\right]$ would exceed the respective levels in competition. As a result, low skill workers would be made relatively worse off.

Proof. In both competition and second degree price discrimination, $q_{H}=q_{L}$ and so the wage premium, given by $w_{H} / w_{L}=h_{H} q_{H} / h_{L} q_{L}$, is left unaffected. Binding incentive compatibility arising from a strictly decreasing $\varepsilon_{\eta}(\theta)$ results in $\eta\left(\theta_{H}\right) / \eta\left(\theta_{L}\right)=$ $h_{H} / h_{L}$, the value that obtains in competition. By (14), the relative rates of employment would differ between the two market structures in as much as $\eta\left(\theta_{L}\right)$ has risen in second degree price discrimination. If $\varepsilon_{\eta}(\theta)$ is strictly decreasing, the effect can be shown to be positive. With the wage premium staying unchanged, the ratio of expected earnings would rise above the level in competition due to the increase in the relative rate of employment. 
In picking qualities and prices to satisfy incentive compatibility, the monopolist's pricing decision would cause the employment prospect of low skill workers to suffer relatively more than the employment prospect of high skill workers in comparison to the benchmark of perfect competition. Specifically, in competition, only when $\left(c_{H} / c_{L}\right)^{\frac{\gamma-1}{\gamma}}<h_{H} / h_{L}$ holds that low skill workers will suffer a bleaker employment prospect. In second degree price discrimination, there tends to be relatively fewer jobs for low skill workers even if $h_{H} / h_{L}=\left(c_{H} / c_{L}\right)^{\frac{\gamma-1}{\gamma}}$ in which case there can be no difference in the rates of employment under competition. In this way, market power intensifies low skill unemployment.

Taking first order condition of (23) with respect to $\theta_{H}$ and substituting in (3) for $q_{H}\left(=q_{L}\right)$ yields

$$
\left(\frac{(1-\beta) \eta\left(\theta_{H}\right) h_{H}}{\gamma}\right)^{\frac{\gamma}{\gamma-1}}\left\{\gamma\left(1+\varepsilon_{\eta}\left(\theta_{H}\right) \frac{n_{H}+n_{L} \frac{\theta_{L}}{\theta_{H}}}{n_{H}+n_{L} \frac{d \theta_{L}}{d \theta_{H}}}\right)-1\right\}=c
$$

where $\theta_{L}$ and $d \theta_{L} / d \theta_{H}$ are implicitly defined by (22). Previously in competition and in first degree price discrimination, both absolute and relative market sizes as given by $\left(n_{H}, n_{L}\right)$ and $n_{H} / n_{L}$ respectively have no effects on employment, productivity and wages. In second degree price discrimination, (24) shows that the model is still scale free for proportional increases in $n_{H}$ and $n_{L}$. But now the relative market size as given by $n_{H} / n_{L}$ apparently does influence equilibrium outcomes.

Proposition 8 In second degree price discrimination and if $\varepsilon_{\eta}(\theta)$ is strictly decreasing, an increase in the relative supply of high skill workers results in more productive equipment offered for sale, raising wages, while dampening job creation and lowering the rates of employment and expected earnings for both skill types.

Proof. If $\varepsilon_{\eta}(\theta)$ is strictly decreasing, the left side of (24) is decreasing in $n_{H} / n_{L}$ and $\theta_{H} \cdot{ }^{13}$ This implies $d \theta_{H} / d\left(\frac{n_{H}}{n_{L}}\right)<0$ and by (22) $\theta_{L}$ is also decreasing in $n_{H} / n_{L}$. By

\footnotetext{
${ }^{13}$ This guarantees that the condition is also sufficient for maximum.
} 
(3) and then by (11), the positive effects on $q_{H}\left(=q_{L}\right), w_{H}$ and $w_{L}$ follow. Expected earnings, given by (12), decline because of the decrease in $\theta_{s}$.

The single quality offered in second degree price discrimination is a compromise of the two distinct qualities in perfect price discrimination. Where exactly the compromise should lie between the two distinct qualities depends on the relative importance of the two markets. An increase in the relative size of the high skill market, in turning this market more important for the monopolist, would induce the firm to pick a more productive machine for sale. That is the case because a more productive machine helps the monopolist extract greater surplus from each firm in the high skill market. The increases in productivity then raise wages. In the meantime, the downstream competitive firms would willingly purchase the more productive machine at a higher price only if the vacancies are filled at high probabilities. Thus the decline in job creation and employment. Expected earnings fall as the negative effects on employment dominate the positive effects on wages.

The proposition implies that a decline in the relative supply of low skill workers will lower the workers' employment and expected earnings. The practical implication is that when more of the population acquire skills, the remaining low skill workers become worse off. This is a peculiar result for it contradicts what one would have expected from a standard demand and supply analysis that decreases in the relative supply of a factor will raise the factor's return. But then since the employment and expected earnings of high skill workers are also adversely affected by the same decline in the relative supply of low skill workers. And if it happens that the effects on high skill workers are more pronounced, the result may not be so peculiar after all. This however is not the case. The decline in the relative supply of low skill workers does harm low skill workers more so than high skill workers.

Proposition 9 In second degree price discrimination and if $\varepsilon_{\eta}(\theta)$ is strictly decreasing, an increase in the relative supply of high skill workers results in increases 
in the relative rate of employment $\mu\left(\theta_{H}\right) / \mu\left(\theta_{L}\right)$ and the ratio if expected earnings $E\left[w_{H}\right] / E\left[w_{L}\right]$

Proof. The relative rate of employment as given in (14) would be affected by the relative supply in as much as $\eta\left(\theta_{L}\right)$ varies with $n_{H} / n_{L}$ since $\eta\left(\theta_{H}\right) / \eta\left(\theta_{L}\right)$ remains at $h_{L} / h_{H}$ throughout. The positive effect on $\mu\left(\theta_{H}\right) / \mu\left(\theta_{L}\right)$ follows because the increase in $\eta\left(\theta_{L}\right)$ that is due to the decline in $\theta_{L}$ has a positive effect on (14) if $\varepsilon_{\eta}(\theta)$ is strictly decreasing. The ratio of expected earnings, given by the product of $w_{H} / w_{L}$ and $\mu\left(\theta_{H}\right) / \mu\left(\theta_{L}\right)$, rises too for the first ratio remains at $h_{H} / h_{L}$, independent of the relative supply of workers.

That an increase in the relative supply of high skill workers will result in deteriorating employment prospects for low skill workers is not a novel result in the job matching literature. In Saint-Paul (1996) and Acemoglu (1997), the hiring of low skill workers involves the opportunity cost of giving up the option that the firm may recruit the more productive high skill workers. There will be such opportunity costs if job creation exhibits decreasing returns in the aggregate. Increases in the relative supply of high skill workers raise the opportunity cost as the prospect of successfully recruiting the more productive high skill workers improves when the supply is more abundant. Filling the job vacancy with low skill workers thus becomes more costly to firms. In these models, the fortunes of high and low skill workers resemble a zero-sum game. More jobs for one skill type are at the expense of less jobs for the other skill type. In the present model, there are more or there are less jobs for both skill types simultaneously when the relative supply varies. This difference makes it possible to distinguish between the two theories. For example, we may track over time whether the employment of both skill types has risen or declined together or whether the employment of high skill workers has risen in the midst of falling employment for low skill workers as the relative supply of high skill workers increases. 


\section{SOCIAL OPTIMALITY}

A social planner would maximize the net output that workers belonging to each skill type may produce.

$$
\mathcal{W}_{s}=\max _{\left\{q_{s}, \theta_{s}\right\}}\left\{n_{s}\left(\mu\left(\theta_{s}\right) h_{s} q_{s}-\theta_{s}\left(c+q_{s}^{\gamma}\right)\right)\right\}
$$

The necessary conditions for optimum are

$$
\begin{gathered}
q_{s}=\left(\frac{\eta\left(\theta_{s}\right) h_{s}}{\gamma}\right)^{\frac{1}{\gamma-1}}, \\
\left(\frac{\eta\left(\theta_{s}\right) h_{s}}{\gamma}\right)^{\frac{\gamma}{\gamma-1}}\left(\gamma\left(1+\varepsilon_{\eta}\left(\theta_{s}\right)\right)-1\right)=c .
\end{gathered}
$$

As in perfect price discrimination, social optimality calls for the same piece of equipment to be sold in either market if $\varepsilon_{\eta}(\theta)$ is constant whereas high skill workers should be equipped with more productive equipment in case $\varepsilon_{\eta}(\theta)$ is strictly decreasing. With the help of (3), (4) and (10) and (24), we may summarize how capital intensity and job creation in the each market structure differ from the social optimum in table 1.

Table 1: The comparison of capital intensity and job creation of various market structures with social optimality

\begin{tabular}{lllll}
\hline & $q_{H}$ & $q_{L}$ & $\theta_{H}$ & $\theta_{L}$ \\
\hline Competition & - & - & $+/-$ & $+/-$ \\
Perfect price discrimination, & & & & \\
$\quad$ (a) $\operatorname{constant} \varepsilon_{\eta}(\theta)$ & 0 & 0 & - & - \\
$\quad$ (b) decreasing $\varepsilon_{\eta}(\theta)$ & - & - & - & - \\
Second degree price discrimination & & & & \\
$\quad$ with a decreasing $\varepsilon_{\eta}(\theta)$ & - & $+/-$ & $+/-$ & - \\
\hline
\end{tabular}


In table 1, a - sign denotes the variable in the market structure concerned falling short of optimality, a + sign denotes the variable exceeding optimality, a $+/-$ means that the comparison is ambiguous and a 0 means that the variable coincides exactly with optimality.

That the quality of the machine chosen in competition is suboptimal is due to the holdup problem noted previously. That job creation may be suboptimal is due to the fact that the fixed cost of job creation is subject to the same holdup problem as well. That it may be excessive is due to the negative externality arising from the fact that an additional vacancy lowers the probability that other vacancies are filled. The overall effect on job creation is ambiguous.

The perfectly discriminating monopolists, in controlling the numbers of vacancies that may be created through its pricing policy, internalizes the negative externality. Only the distortion arising from the holdup problem associated with the fixed cost of job creation remains and this unambiguously lowers job creation below optimality. In case $\varepsilon_{\eta}(\theta)$ is constant, the positive effect of monopoly pricing on machine qualities exactly cancel out the negative effect of the holdup problem, restoring optimality in the quality choice. In case $\varepsilon_{\eta}(\theta)$ is decreasing, the negative effects of the holdup problem dominates, leaving overall negative effects on machine qualities.

In second degree price discrimination, the monopolist in picking a machine quality lying somewhere in-between the two qualities in perfect price discrimination, lowers the quality in the high skill market below the quality in perfect price discrimination. Since the quality in the latter is suboptimal to begin with, the machine quality in second degree price discrimination is likewise suboptimal. A similar conclusion on low skill job creation applies as firms hiring low skill workers will be required to purchase more costly equipment than in perfect price discrimination and low skill job creation in the latter is suboptimal in the first place. On the other hand, that firms hiring high skill workers may now invest in less costly equipment raises high 
skill job creation in second degree price discrimination above high skill job creation in perfect price discrimination. If the increase is sufficiently pronounced, it may even rise above high skill job creation in social optimum. But that can only happen if high skill job creation in competition happens to be excessive since job creation in price discrimination of any degrees falls short of job creation in competition. The comparison of machine quality in the low skill market may be interpreted similarly.

\section{CONCLUDING REMARKS}

How product market competition affects the labour market is a relatively unexploited question that deserves more attention. In this paper, I study a channel in which monopoly in capital equipment hurts workers in general and more so for low skill workers. The empirical importance of the channel remains to be seen. But this should not be a difficult task as it only involves checking whether product market competition in the upstream industry has any effects on the relative rate of employment between high skill and low skill workers in the downstream industry.

\section{REFERENCES}

[1] Acemoglu, Daron, 1997, "Matching, heterogeneity, and the evolution of income distribution," Journal of Economic Growth, 2, 61-92.

[2] Akerlof, George, 1969, "Structural unemployment in a neo-classical framework", Journal of Political Economy, 399-407.

[3] Blanchard, Olivier and Peter Diamond, 1990, "The aggregate matching function," in Peter Diamond (ed.), Productivity, Growth and Unemployment: Essays in Honor of Robert Solow's Birthday, MIT Press. 
[4] Hosios, Arthur J., 1990, "On the efficiency of matching and related models of search and unemployment," Review of Economic Studies, 57, 279-298.

[5] Ordover, Januz and John Panzar, 1982, "On the nonlinear pricing of inputs," International Economic Review, 23, 659-675.

[6] Machin, Stephen and Alan Manning, 1997, "Can supply create its own demand? Implications for rising skill differentials", European Economic Review, 41, 507516.

[7] Mortensen, Dale and Christopher Pissarides, 1999, "Unemployment responses to skillbiased technology shocks: the role of labour market policy," Economic Journal, 109, 242-265.

[8] Mussa, Michael and Sherwin Rosen, 1978, "Monopoly and product quality," Journal of Economic Theory, 18, 301-317.

[9] Nickell, Stephen, 1999, "Product markets and labor markets," Labour Economics, 6, 1-20.

[10] Pissarides, Christopher, 1990, Equilibrium unemployment theory, Blackwell Publishers.

[11] Saint-Paul, Gilles, 1996, "Are the unemployed unemployable," European Economic Review, 40, 1501-1519. 


\section{APPENDIX (NOT TO BE CONSIDERED FOR PUBLICATION)}

\section{A. The hypothetical solution of second degree price discrimination}

In this section, I prove the claim in the main text that the maximization of

$$
\Pi=n_{H} \theta_{H}\left(p_{H}-q_{H}^{\gamma}\right)+n_{L} \theta_{L}\left(p_{L}-q_{L}^{\gamma}\right)
$$

subject to the participation constraints:

$$
\begin{aligned}
\eta\left(\theta_{H}\right)(1-\beta) h_{H} q_{H}-p_{H} & \geq c \\
\eta\left(\theta_{L}\right)(1-\beta) h_{L} q_{L}-p_{L} & \geq c
\end{aligned}
$$

and the incentive compatibility constraints:

$$
\begin{aligned}
\eta\left(\theta_{H}\right)(1-\beta) h_{H} q_{H}-p_{H} & \geq \eta\left(\theta_{H}\right)(1-\beta) h_{H} q_{L}-p_{L} \\
\eta\left(\theta_{L}\right)(1-\beta) h_{L} q_{L}-p_{L} & \geq \eta\left(\theta_{L}\right)(1-\beta) h_{L} q_{H}-p_{H}
\end{aligned}
$$

results in firms posting vacancies in the high skill market enjoying a certain positive surplus if it is optimal for the monopolist to discriminate between the two markets. Call this problem $M$.

For the participation constraints may hold as strict inequalities, the monopolist in general can pick the quantity independently of the price and quality of the machines offered for sale in each market. Formally, the choice variables are $\left\{q_{H}, p_{H}, \theta_{H}, q_{L}, p_{L}, \theta_{L}\right\}$. The choices of $\left\{\theta_{H}, \theta_{L}\right\}$ are merely choices of quantities of machines to be sold as $v_{s}=n_{s} \theta_{s}$. We proceed by assuming that incentive compatibility is not binding in the low skill market under which we can ignore (28). Then increases in $p_{L}$ not only will raise the monopolist's profit, other things equal, but will also enlarge the choice set defined by (27). Hence if incentive compatibility for the low skill market is indeed not binding, (26) must hold as an equality in the monopolist's profit maximization. Next rewrite (25) as

$$
\eta\left(\theta_{H}\right)(1-\beta) h_{H} q_{H}-p_{H}-x=c
$$


for some $x \geq 0$ to allow for the monopolist leaving a certain positive surplus for firms in the high skill market. Plugging the above and (26) holding as an equality into (27) yields

$$
x \geq q_{L}(1-\beta)\left(\eta\left(\theta_{H}\right) h_{H}-\eta\left(\theta_{L}\right) h_{L}\right)
$$

Plugging (29) and (26) holding as an equality into the profit function yields

$$
\Pi=n_{H} \theta_{H}\left(\eta\left(\theta_{H}\right)(1-\beta) h_{H} q_{H}-x-c-q_{H}^{\gamma}\right)+n_{L} \theta_{L}\left(\eta\left(\theta_{L}\right)(1-\beta) h_{L} q_{L}-c-q_{L}^{\gamma}\right) .
$$

Assuming incentive compatibility in the low skill market is not binding and employing an additional variable $x$, we simplify $M$ to the maximization of (31) subject to (30) and where the choice variables are now $\left\{q_{H}, x, \theta_{H}, q_{L}, \theta_{L}\right\}$. Denoting $\lambda$ as the Lagrangian multiplier associated with (30), the first order conditions are

$$
\begin{gathered}
q_{H}: \eta\left(\theta_{H}\right)(1-\beta) h_{H}-\gamma q_{H}^{\gamma-1}=0, \\
q_{L}: n_{L} \theta_{L}\left(\eta\left(\theta_{L}\right)(1-\beta) h_{L}-\gamma q_{L}^{\gamma-1}\right)-\lambda(1-\beta)\left(\eta\left(\theta_{H}\right) h_{H}-\eta\left(\theta_{L}\right) h_{L}\right)=0, \\
x:-n_{H} \theta_{H}+\lambda \leq 0, \quad x \geq 0, \\
\lambda: x \geq q_{L}(1-\beta)\left(\eta\left(\theta_{H}\right) h_{H}-\eta\left(\theta_{L}\right) h_{L}\right), \quad \lambda \geq 0, \\
\theta_{H}: n_{H}\left(\eta\left(\theta_{H}\right)(1-\beta) h_{H} q_{H}-x-c-q_{H}^{\gamma}+\theta_{H} \eta^{\prime}\left(\theta_{H}\right)(1-\beta) h_{H} q_{H}\right)- \\
\lambda(1-\beta) q_{L} \eta^{\prime}\left(\theta_{H}\right) h_{H}=0, \\
\theta_{L}: n_{L}\left(\eta\left(\theta_{L}\right)(1-\beta) h_{L} q_{L}-c-q_{L}^{\gamma}+\theta_{L} \eta^{\prime}\left(\theta_{L}\right)(1-\beta) h_{L} q_{L}\right)- \\
\lambda(1-\beta) q_{L} \eta^{\prime}\left(\theta_{L}\right) h_{L}=0 .
\end{gathered}
$$

A priori, we do not know for sure whether incentive compatibility will be binding and whether it is optimal for the monopolist to leave a certain surplus to firms in the high skill market. And so we have made allowance for $x$ and $\lambda$ to be corner solutions in the above. 
Suppose incentive compatibility is not binding. In this case, $\lambda=0$. Then it follows from (34) that $x=0$ too. Equations (32) is identical to the corresponding first order condition in the unconstrained solution in the first place and with $\lambda=0$, the same conclusion on $(33),(36)$ and (37) follows. If $\varepsilon_{\eta}(\theta)$ is constant, the analysis of perfect price discrimination in the text indicates that $\eta\left(\theta_{H}\right) h_{H}-\eta\left(\theta_{L}\right) h_{L}=0$, thus satisfying (35). This verifies that incentive compatibility is in fact not binding in this case. $^{14}$

But with a strictly decreasing $\varepsilon_{\eta}(\theta)$, the unconstrained solution would violate incentive compatibility in the high skill market. In this case, $\lambda>0$ and (35) holds as an equality. Our task is to show that it is optimal for the monopolist to set $x>0$. To do so, we momentarily drop the non-negativity constraint on $x$ to allow counterfactually that $x$ may take on negative values. Then (34) must hold as an equality and hence $\lambda=n_{H} \theta_{H}$. This turns (36) into

$$
\eta\left(\theta_{H}\right)(1-\beta) h_{H} q_{H}-x-c-q_{H}^{\gamma}+\theta_{H}(1-\beta) \eta^{\prime}\left(\theta_{H}\right) h_{H}\left(q_{H}-q_{L}\right)=0
$$

If $x \leq 0$ holds in the absence of the non-negativity constraint, we have from $(35), \eta\left(\theta_{H}\right) h_{H^{-}}$ $\eta\left(\theta_{L}\right) h_{L} \leq 0$. And then by (32) and (33), $q_{L} \geq q_{H}$ under which we must have $\eta\left(\theta_{H}\right)(1-\beta) h_{H} q_{H}-x-c-q_{H}^{\gamma} \leq 0$ for (38) to be satisfied. Yet, as the per unit revenue the monopolist earns in the high skill market, this clearly must be strictly positive in the optimal solution. This proves that $x>0$ in the monopolist's profit maximization. Then by (35)

$$
\eta\left(\theta_{H}\right) h_{H}-\eta\left(\theta_{L}\right) h_{L}>0
$$

and by (32) and (33)

$$
q_{H}>q_{L}
$$

\footnotetext{
${ }^{14}$ The incentive compatibility constraint in the low skill market is $d \geq$ $q_{H}(1-\beta)\left(\eta\left(\theta_{L}\right) h_{L}-\eta\left(\theta_{H}\right) h_{H}\right)$ where $d$ denotes the surplus the monopolist may leave to firms in the low skill market. This clearly is also satisfied with $d=0$.
} 
Next we turn to incentive compatibility in the low skill market. Substituting (26) and (30) holding as equalities and (29) into (28), we have the incentive compatibility constraint in the low skill market simplified to

$$
0 \geq(1-\beta)\left(q_{H}-q_{L}\right)\left(\eta\left(\theta_{L}\right) h_{L}-\eta\left(\theta_{H}\right) h_{L}\right)
$$

which holds with strict inequality by virtue of (39) and (40). Our previous presumption that incentive compatibility in the low skill market is not binding is hence justified.

Finally, we may show that the monopolist offers a more productive machine in the high skill market than the machine chosen in competition but a less productive machine in the low skill market. First, recall from proposition 1 in the main text that in all cases, $\theta_{s}^{m}<\theta_{s}^{c}$ for $s=H$ and $L$ where the superscript $m$ stands for monopoly and $c$ for competition. For the high skill market, we have the machine quality given by (32) in either market structure and with $\eta\left(\theta_{H}^{m}\right)>\eta\left(\theta_{H}^{c}\right)$, the claim follows. To prove the claim for the low skill market, we define

$$
q^{\prime}=\arg \max _{q}\left\{\eta\left(\theta_{L}^{m}\right)(1-\beta) h_{L} q-q^{\gamma}\right\}
$$

With $\lambda>0$ and by (33) and (39), $q_{L}^{m}<q^{\prime}$. Suppose contrary to the claim we have instead $q_{L}^{m} \geq q_{L}^{c}$. Then

$$
\eta\left(\theta_{L}^{m}\right)(1-\beta) h_{L} q_{L}^{c}-\left(q_{L}^{c}\right)^{\gamma} \leq \eta\left(\theta_{L}^{m}\right)(1-\beta) h_{L} q_{L}^{m}-\left(q_{L}^{m}\right)^{\gamma}=c
$$

where the inequality follows from the strict concavity of the function defined in (41) and the fact that $q_{L}^{m}<q^{\prime}$. Yet since $\eta\left(\theta_{L}^{m}\right)>\eta\left(\theta_{L}^{c}\right)$,

$$
\eta\left(\theta_{L}^{m}\right)(1-\beta) h_{L} q_{L}^{c}-\left(q_{L}^{c}\right)^{\gamma}>\eta\left(\theta_{L}^{c}\right)(1-\beta) h_{L} q_{L}^{c}-\left(q_{L}^{c}\right)^{\gamma}=c
$$

The hypothesis of $q_{L}^{m} \geq q_{L}^{c}$ thus results in a contradiction and the claim for the low skill market follows. 


\section{B. Post-match Investment}

\section{B1. Environment.-}

In this appendix, I repeat the analysis in the main text under the alternative timing assumption that firms may purchase the capital equipment only after jobs are filled. The purpose is to show that the more important results survive the change in the timing assumption. Specifically, now assume that the order of events is as follows:

(i) Firms pay $c$ to post a vacancy for either $H$ or $L$ workers.

(ii) Matches are formed and firms whose vacancies are filled may proceed to invest in physical capital.

(iii) Production commences and the worker-firm pair divides the surplus.

In the second stage, the worker-firm pair in the market for type $s=H$ and $L$ workers makes the investment choice via

$$
J_{s}=\max _{q}\left\{h_{s} q-p(q)\right\} .
$$

Because investment in physical capital is made only after job matches are formed, the appropriable surplus is just the net output of the job match. The expected return on job creation is thus

$$
R\left(\theta_{s}\right)=\eta\left(\theta_{s}\right)(1-\beta) J_{s}-c .
$$

\section{B2. Competitive benchmark.-}

In the competitive benchmark with $p(q)=q^{\gamma}$, solving (42) yields

$$
q_{s}=\left(\frac{h_{s}}{\gamma}\right)^{\frac{1}{\gamma-1}}
$$

Given that investment is undertaken after job matches are formed, the investment choice is efficient. In equilibrium, the expected return on job creation is driven down 
to $0^{15}$

$$
\eta\left(\theta_{s}\right)(1-\beta)\left(\frac{h_{s}}{\gamma}\right)^{\frac{\gamma}{\gamma-1}}(\gamma-1)=c .
$$

With $h_{H}>h_{L}$, (45) implies that $\theta_{H}>\theta_{L}$ and so high skill workers do enjoy better employment prospects. As expected, we have $w_{H}>w_{L}$ as well. That is the case since wages as given by

$$
w_{s}=\beta J_{s}=\beta\left(\frac{h_{s}}{\gamma}\right)^{\frac{\gamma}{\gamma-1}}(\gamma-1)
$$

are solely functions of the workers' innate productivity.

\section{B3. Monopoly.-}

The number of machines that will be sold in a market is equal to the number of filled vacancies $v_{s} \eta\left(\theta_{s}\right)=n_{s} \theta_{s} \eta\left(\theta_{s}\right)$. The monopolist's profit function is given by

$$
\Pi=n_{H} \theta_{H} \eta\left(\theta_{H}\right)\left(p_{H}-q_{H}^{\gamma}\right)-n_{L} \theta_{L} \eta\left(\theta_{L}\right)\left(p_{L}-q_{L}^{\gamma}\right) .
$$

The profit maximization is subject to the participation constraints that the downstream competitive firms earn non-negative expected return on job creation. From (42) and (43), the price to charge cannot exceed:

$$
p_{s} \leq h_{s} q_{s}-\frac{c}{\eta\left(\theta_{s}\right)(1-\beta)} .
$$

We can first establish that proposition 1 in the main text continues to hold

Proposition 10 The monopolist will set prices, qualities and quantities such that there will be fewer job vacancies created for both skill types compared to the benchmark of a perfectly competitive equipment market. Employment declines as a result. And the vacancies created will be filled at higher probabilities.

\footnotetext{
${ }^{15} \mathrm{~A}$ positive number of jobs are created in equilibrium if and only if $(1-\beta)\left(\frac{h_{s}}{\gamma}\right)^{\frac{\gamma}{\gamma-1}}(\gamma-1)>c$ which I assume to hold throughout.
} 
Proof. Let $\theta_{s}^{c}$ and $\theta_{s}^{m}$ be respectively the market tightness in competition and monopoly for market $s$. The monopolist obviously will pick the price, quality and quantity offered for sale in each market to earn strictly positive profits for it always has the option to entirely shut down the market concerned. From (47) and (48), this implies

$$
h_{s} q_{s}-\frac{c}{\eta\left(\theta_{s}\right)(1-\beta)}-q_{s}^{\gamma}>0
$$

in monopoly. If if $\eta\left(\theta_{s}^{c}\right) \geq \eta\left(\theta_{s}^{m}\right)$,

$$
0=\max _{q}\left\{h_{s} q-q^{\gamma}\right\}-\frac{c}{\eta\left(\theta_{s}^{c}\right)(1-\beta)} \geq h_{s} q_{s}-\frac{c}{\eta\left(\theta_{s}\right)(1-\beta)}-q_{s}^{\gamma}
$$

for any $q_{s}$, which contradicts (49). We must then have $\eta\left(\theta_{s}^{c}\right)<\eta\left(\theta_{s}^{m}\right)$ and $\theta_{s}^{c}>\theta_{s}^{m}$.

We first analyze perfect price discrimination. The right side of (48) defines the maximum price that may be charged for a given $\left(q_{s}, \theta_{s}\right)$ pair. Absent the necessity to be concerned with incentive compatibility in second degree price discrimination, the monopolist would find it optimal to charge just the maximum. Substituting (48) holding as equalities into (47) yields

$$
\begin{aligned}
\Pi=n_{H} \theta_{H} \eta\left(\theta_{H}\right)( & \left.h_{H} q_{H}-\frac{c}{\eta\left(\theta_{H}\right)(1-\beta)}-q_{H}^{\gamma}\right)+ \\
& n_{L} \theta_{L} \eta\left(\theta_{L}\right)\left(h_{L} q_{L}-\frac{c}{\eta\left(\theta_{L}\right)(1-\beta)}-q_{L}^{\gamma}\right) .
\end{aligned}
$$

Proposition 11 In perfect price discrimination, the quality offered to each market is identical to the quality chosen in competition but at a high price, lowering the match surplus while leaving no effects on productivity. This cause wages and expected earnings for both skill types to go down.

Proof. Taking first order condition of (50) with respect to $q_{H}$ and $q_{L}$ yields exactly (44). Hence there is no difference in the qualities of machines sold and the productivity of the job matches across the two market structures. By virtue of $(42),(43)$ and a 
zero expected return condition on job creation, the prices in competition satisfies

$$
p_{s}=h_{s} q_{s}-\frac{c}{\eta\left(\theta_{s}\right)(1-\beta)}
$$

that also holds in first degree price discrimination. The lowering of $\theta_{s}$ in monopoly pricing raises $\eta\left(\theta_{s}\right)$ and consequently the right side of the above. Wages, given by

$$
w_{s}=\beta J_{s}=\beta\left(h_{s} q_{s}-p_{s}\right)
$$

fall below the level in competition as physical capital investment becomes more costly. Given the decline in the probability of employment due to lower job creation, the same conclusion on expected earnings, given by

$$
E\left[w_{s}\right]=\mu\left(\theta_{s}\right) \beta J_{s}
$$

follows.

Taking first order condition of (50) with respect to $\theta_{s}, s=H$ and $L$ and then substituting in (44) for $q_{s}$ yields

$$
\eta\left(\theta_{s}\right)(1-\beta)\left(1+\varepsilon_{\eta}\left(\theta_{s}\right)\right)\left(\frac{h_{s}}{\gamma}\right)^{\frac{\gamma}{\gamma-1}}(\gamma-1)=c .
$$

I should assume that the regularity conditions on the matching function discussed in the main text continue to hold, which happens to guarantee that the above is uniquely solved by some $\theta_{s}$ as well as sufficient for maximum. With $\varepsilon_{\eta}(\theta)$ nonincreasing, the condition immediately ensures that $\theta_{H}>\theta_{L}$ and so high skill workers continue enjoying better employment prospects. As to how one skill type fares against the other in comparison to competition, we can show that

Proposition 12 If $\varepsilon_{\eta}(\theta)$ is constant, perfect price discrimination has no effects on the wage premium $w_{H} / w_{L}$, the relative rate of employment $\mu\left(\theta_{H}\right) / \mu\left(\theta_{L}\right)$ and the $r a-$ tio of expected earnings $E\left[w_{H}\right] / E\left[w_{L}\right]$ relative to the respective levels in competition. 
If $\varepsilon_{\eta}(\theta)$ is decreasing, the wage premium is lowered while the relative rate of employment and the ratio of expected earning may rise or fall below the respective levels in competition.

Proof. By (51) and (52), the wage premium in either competition or perfect price discrimination is given by

$$
\frac{w_{H}}{w_{L}}=\left(\frac{\eta\left(\theta_{H}\right)}{\eta\left(\theta_{L}\right)}\right)^{-1}
$$

By $(45)$

$$
\frac{\eta\left(\theta_{H}\right)}{\eta\left(\theta_{L}\right)}=\left(\frac{h_{L}}{h_{H}}\right)^{\frac{\gamma}{\gamma-1}}
$$

in competition and by (53)

$$
\frac{\eta\left(\theta_{H}\right)}{\eta\left(\theta_{L}\right)}=\left(\frac{h_{L}}{h_{H}}\right)^{\frac{\gamma}{\gamma-1}} \frac{1+\varepsilon_{\eta}\left(\theta_{L}\right)}{1+\varepsilon_{\eta}\left(\theta_{H}\right)}
$$

in perfect price discrimination. If $\varepsilon_{\eta}(\theta)$ is constant, (56) reduces to (55) and so the wage premium stays unaltered. If $\varepsilon_{\eta}(\theta)$ is decreasing, $\varepsilon_{\eta}\left(\theta_{L}\right)>\varepsilon_{\eta}\left(\theta_{H}\right)$ and so (56) exceeds (55), lowering the wage premium. In case $\varepsilon_{\eta}(\theta)$ is constant, the invariance of $\eta\left(\theta_{H}\right) / \eta\left(\theta_{L}\right)$ across the two market structures implies that the relative rate of employment $\mu\left(\theta_{H}\right) / \mu\left(\theta_{L}\right)$ as given by (14) in the main text would change in so far as $\eta\left(\theta_{L}\right)$ differs between the two market structures. But precisely when $\varepsilon_{\eta}(\theta)$ is constant that (14) is independent of $\eta\left(\theta_{L}\right)$ for given $\eta_{H} / \eta_{L}$. Hence the invariance of the relative rate of employment. If $\varepsilon_{\eta}(\theta)$ is decreasing, perfect price discrimination has no systematic effects on the relative rate of employment in comparison to competition. In reference to (14), first there is the negative effect of a higher $\eta\left(\theta_{H}\right) / \eta\left(\theta_{L}\right)$ and then the positive effect of a higher $\eta\left(\theta_{L}\right)$. No general conclusion is available as to whether the positive or the negative effect will dominate. If $\varepsilon_{\eta}(\theta)$ is constant, neither the relative rate of employment nor the wage premium is affected by perfect price discrimination and so the same conclusion on the ratio of expected earnings follows. In case $\varepsilon_{\eta}(\theta)$ is decreasing, the ambiguity as to how the relative rate of 
employment differs between the two market structures carries over to whether the ratio of expected earnings in perfect price discrimination would exceed or fall below the ratio in competition.

In conclusion, perfect price discrimination leaves no effects on machine qualities and productivity but lowers employment, wages and expected earnings of both skill types. Nevertheless, one skill type is not particularly adversely affected relative to the other.

Next, we move on to the case of second degree price discrimination. Absent the ability to observe the buyers' types directly, the prices and qualities the monopolist may pick are restricted by the two incentive compatibility constraints:

$$
\begin{aligned}
h_{H} q_{H}-p_{H} & \geq h_{H} q_{L}-p_{L}, \\
h_{L} q_{L}-p_{L} & \geq h_{L} q_{H}-p_{H} .
\end{aligned}
$$

Is first degree price discrimination incentive compatible? To answer the question, we substitute (51) and (53) into the above yielding respectively

$$
\begin{gathered}
\frac{\gamma-1}{\gamma}\left(\left(1+\varepsilon_{\eta}\left(\theta_{H}\right)\right)\left(\frac{h_{H}}{h_{L}}\right)^{\frac{\gamma}{\gamma-1}}-\left(1+\varepsilon_{\eta}\left(\theta_{L}\right)\right)\right)-\frac{h_{H}}{h_{L}}+1 \geq 0 \\
\left(\frac{\gamma-1}{\gamma}\left(1+\varepsilon_{\eta}\left(\theta_{H}\right)\right)-1\right)\left(\frac{h_{H}}{h_{L}}\right)^{\frac{\gamma}{\gamma-1}}+\left(\frac{h_{H}}{h_{L}}\right)^{\frac{1}{\gamma-1}}-\frac{\gamma-1}{\gamma}\left(1+\varepsilon_{\eta}\left(\theta_{L}\right)\right) \leq 0 .
\end{gathered}
$$

The second inequality holds for all $h_{H} / h_{L}>1$ given that $\varepsilon_{\eta}\left(\theta_{L}\right) \geq \varepsilon_{\eta}\left(\theta_{H}\right)$ and so first degree price discrimination satisfies incentive compatibility in the low skill market. Whether or not the first inequality holds depends on the ratio $h_{H} / h_{L}$ as well as on the shape of the $\varepsilon_{\eta}(\theta)$ function. Since the left side is non-positive at $h_{H} / h_{L}=1$ for $\varepsilon_{\eta}\left(\theta_{L}\right) \geq \varepsilon_{\eta}\left(\theta_{H}\right)$ and decreasing in $h_{H} / h_{L}$ for small $h_{H} / h_{L}$, first degree price discrimination must fail incentive compatibility in the high skill market for small $h_{H} / h_{L}$. For a constant $\varepsilon_{\eta}(\theta)$, it can be shown that the inequality is satisfied for $h_{H} / h_{L}$ exceeding some minimum level. Hence in case $\varepsilon_{\eta}(\theta)$ is constant, first and 
second degree price discriminations are equivalent if and only if the productivity differential between the skill types is sufficiently pronounced.

Does the standard result from the monopoly pricing literature that it is optimal for the monopolist to satisfy incentive compatibility by leaving a certain positive expected surplus to high demand buyers that are firms posting vacancies in the high skill market in the present situation apply? In particular, is it optimal for the monopolist to leave the participation constraint in (48) in the high skill market holding as a strict inequality? First, some zero expected return condition on job creation in each market must hold in the present case with physical capital investment taking place only after jobs are filled. For job vacancies can be created without first investing in physical capital. Free entry must then drive down the expected return on job creation in each market to zero. Now if the monopolist ever tries to restrict output in not meeting all demand in the market for the high quality machines, then not all matched firm-worker pairs can go ahead to commence production. Equilibrium in job creation in the high skill market is characterized by (48) holding as an equality with $\eta\left(\theta_{H}\right)$ replaced by $u \eta\left(\theta_{H}\right)$ for some $u$ denoting the ratio of the number of matched worker-firm pairs and the number of high quality machines supplied.

Can such rationing policies be optimal for the monopolist? Limiting the supply may help attaining incentive compatibility in the high skill market in as much as it may lower $p_{H}$ or raising $q_{H}$ or both. But so long as the changes in prices and qualities have restored incentive compatibility in the high skill market as given by (57), the monopolist's profit is strictly increasing in the number of high quality machines sold. For a given $\left(p_{H}, q_{H}\right)$ pair, the maximum number of machines that can be sold is given by a $\theta_{H}$ that solves $(48)$ as an equality. In all, the participation constraints for the high skill, as well as the low skill, markets must still hold in second degree price discrimination.

To analyze second degree price discrimination, we can then substituting in the 
participation constraints holding as equalities into the incentive compatibility in the high skill market (57) yielding

$$
\eta\left(\theta_{H}\right) \geq \eta\left(\theta_{L}\right)\left(1+\eta\left(\theta_{L}\right) q_{L}\left(h_{H}-h_{L}\right) \frac{1-\beta}{c}\right)^{-1}
$$

The profit maximization is thus the maximization of (50) subject to (59). By mere inspection, we can see that (44) continues to hold for $q_{H}$. With incentive compatibility binding, the first order conditions with respect to $q_{L}$ and $\theta_{L}$ are respectively

$$
\begin{gathered}
q_{L}=\left\{\frac{h_{L}}{\gamma}+\frac{1}{\gamma \theta_{L} \eta\left(\theta_{L}\right)} \frac{n_{H}}{n_{L}} \frac{\partial \theta_{H}}{\partial q_{L}}\left(\eta\left(\theta_{H}\right)\left(1+\varepsilon_{\eta}\left(\theta_{H}\right)\right)\left(\frac{h_{H}}{\gamma}\right)^{\frac{\gamma}{\gamma-1}}(\gamma-1)-\frac{c}{1-\beta}\right)\right\}_{(60)}^{\frac{1}{\gamma-1}} \\
\eta\left(\theta_{L}\right)\left(1+\varepsilon_{\eta}\left(\theta_{L}\right)\right)\left(h_{L} q_{L}-q_{L}^{\gamma}\right)-\frac{c}{1-\beta}+ \\
\frac{n_{H}}{n_{L}} \frac{\partial \theta_{H}}{\partial \theta_{L}}\left(\eta\left(\theta_{H}\right)\left(1+\varepsilon_{\eta}\left(\theta_{H}\right)\right)\left(\frac{h_{H}}{\gamma}\right)^{\frac{\gamma}{\gamma-1}}(\gamma-1)-\frac{c}{1-\beta}\right)=0
\end{gathered}
$$

where $\theta_{H}, \partial \theta_{H} / \partial q_{L}$ and $\partial \theta_{H} / \partial \theta_{L}$ are functions of $q_{L}$ and $\theta_{L}$, implicitly defined by (59) holding as an equality. It can be easily verified that both partials are positive.

Proposition 13 In comparison to the competitive benchmark, second degree price discrimination with binding incentive compatibility has no effect on the quality in the high skill market, but lowers the quality in the low skill market. Furthermore, wages and expected earnings for both skill type are lowered.

Proof. First $q_{L} \neq q_{L}^{\prime}=\arg \max _{q}\left\{h_{L} q_{L}-q_{L}^{\gamma}\right\}$ that is the level in competition and first degree price discrimination. For if they are equal, (60) and (61) imply that the price-quality pairs in both markets are identical to the respective price-quality pairs in first degree price discrimination. And that we presume is not incentive compatible in the first place. Now suppose $q_{L}>q_{L}^{\prime}$. Consider what happens when $q_{L}$ is lowered while $\theta_{H}$ and $\theta_{L}$ are held constant. By (59), this adjustment does not violate incentive 
compatibility if the initial triple of $\left(q_{L}, \theta_{H}, \theta_{L}\right)$ are incentive compatible. The profit earned from the high skill matches are not affected by the change with $q_{H}$ and $\theta_{H}$ unaltered. The profit earned from the low skill market by virtue of (50) rises instead with $\theta_{L}$ unaltered and $q_{L}$ now closer to the ideal of $q_{L}^{\prime}$. And so any $q_{L}>q_{L}^{\prime}$ cannot be profit maximizing.

Substituting the participation constraints (48) holding as equalities into the wage equations in (52)

$$
w_{s}=\frac{\beta}{1-\beta} \frac{c}{\eta\left(\theta_{s}\right)} \quad \text { for } s=H \text { and } L .
$$

The lowering of $\theta_{s}$ in any monopoly pricing scheme thus also lowers wages in both markets. The same conclusion on expected earnings follow as the probabilities of employment are lowered too by the falling market tightness.

Proposition 14 The wage premium $w_{H} / w_{L}$, the relative rate of employment $\mu\left(\theta_{H}\right) / \mu\left(\theta_{L}\right)$ and the ratio of expected earnings $E\left[w_{H}\right] / E\left[w_{L}\right]$ in second degree price discrimination with binding incentive compatibility rise above the respective levels in perfect price discrimination. If $\varepsilon_{\eta}(\theta)$ is constant, the same conclusion carries over to the comparison with competition.

Proof. The proof proceeds by first establishing that second degree price discrimination with binding incentive compatibility lowers $\eta\left(\theta_{H}\right) / \eta\left(\theta_{L}\right)$ below the level in first degree price discrimination. Suppose $\theta_{L} \geq \theta_{L}^{f}$ and so $\eta\left(\theta_{L}\right) \leq \eta\left(\theta_{L}^{f}\right)$ where variables with superscript $f$ denote values in first degree price discrimination. Then

$$
\begin{aligned}
\eta\left(\theta_{L}\right)\left(1+\varepsilon_{\eta}\left(\theta_{L}\right)\right)\left(h_{L} q_{L}-q_{L}^{\gamma}\right)-\frac{c}{1-\beta} \leq \\
\eta\left(\theta_{L}^{f}\right)\left(1+\varepsilon_{\eta}\left(\theta_{L}^{f}\right)\right)\left(h_{L} q_{L}^{f}-\left(q_{L}^{f}\right)^{\gamma}\right)-\frac{c}{1-\beta}
\end{aligned}
$$

since $\varepsilon_{\eta}(\theta)$ is non-increasing and $q_{L}^{f}=\arg \max _{q}\left\{h_{L} q_{L}-q\right\}$. The second line by (53) vanishes and this implies the first line is non-positive. And so the second line of (61) 
must be non-negative. But if that is the case, $q_{L} \geq q_{L}^{f}$, contradicting proposition 13 . This proves $\theta_{L}<\theta_{L}^{f}$ and so $\eta\left(\theta_{L}\right)>\eta\left(\theta_{L}^{f}\right)$. That $q_{L}<q_{L}^{f}$, by (51), implies that

$$
\begin{aligned}
& \eta\left(\theta_{H}\right)\left(1+\varepsilon_{\eta}\left(\theta_{H}\right)\right)\left(\frac{h_{H}}{\gamma}\right)^{\frac{\gamma}{\gamma-1}}(\gamma-1)-\frac{c}{1-\beta}<0 \\
= & \eta\left(\theta_{H}^{f}\right)\left(1+\varepsilon_{\eta}\left(\theta_{H}^{f}\right)\right)\left(\frac{h_{H}}{\gamma}\right)^{\frac{\gamma}{\gamma-1}}(\gamma-1)-\frac{c}{1-\beta}
\end{aligned}
$$

where the equality in the second line is again by virtue of (53). It follows then $\theta_{H}>\theta_{H}^{f}$ and $\eta\left(\theta_{H}\right)<\eta\left(\theta_{H}^{f}\right)$. This establishes $\eta\left(\theta_{H}\right) / \eta\left(\theta_{L}\right)<\eta\left(\theta_{H}^{f}\right) / \eta\left(\theta_{L}^{f}\right)$. With the participation constraints continue to hold as equalities in second degree price discrimination, the wage premium remains at (54). The lowering of $\eta\left(\theta_{H}\right) / \eta\left(\theta_{L}\right)$ thus raises the wage premium above the level in perfect price discrimination. The relative rate of employment as given by (14) in the main text likewise rises above the level in perfect price discrimination by the decline in $\eta\left(\theta_{H}\right) / \eta\left(\theta_{L}\right)$ and the increase in $\eta\left(\theta_{L}\right)$. The same conclusion on the ratio of expected earnings then follows. If $\varepsilon_{\eta}(\theta)$ is constant, the wage premium, the relative rate of employment and the ratio of expected earnings in perfect price discrimination are identical to the respective values in competition. Thus in this case, second degree price discrimination raises them all above the respective values in competition.

That $\varepsilon_{\eta}(\theta)$ is constant is only a sufficient but not necessary condition for low skill workers to be made relatively worse off in second degree price discrimination in comparison to competition. In case $\varepsilon_{\eta}(\theta)$ is strictly decreasing, there does not appear possible to establish any unambiguous comparisons. On the other hand, the following proposition on the comparative statics of the relative supply of workers holds so long as $\varepsilon_{\eta}(\theta)$ is non-increasing.

Proposition 15 In second degree price discrimination with binding incentive compatibility, an increase in the relative supply of high skill workers lowers the quality of 
machines sold in the low skill market and the employment and wages for both skill types.

Proof. At $n_{H}=0,(60)$ and (61) imply that $q_{L}=q_{L}^{f}$ and $\theta_{L}=\theta_{L}^{f}$. This should be the case since in the absence of a high skill market, there can be no price discrimination of any degree. By proposition 13, $q_{L}<q_{L}^{f}$ and $\theta_{L}<\theta_{L}^{f}$ for any $n_{H}>0$. Hence $\partial q_{L} / \partial n_{H}<0$ and $\partial \theta_{L} / \partial n_{H}<0$ must hold for small $n_{H}$. If the two partials do not change sign, they will be negative throughout. Now suppose that one or both do change sign at some $n_{H}$, then $\partial q_{L} / \partial n_{H}=0$ or $\partial \theta_{L} / \partial n_{H}=0$ or both hold at the point where the partials become positive. Obviously (60) and (61) require that at least one of $\partial q_{L} / \partial n_{H}$ and $\partial \theta_{L} / \partial n_{H}$ not vanish. Furthermore, the profit function (50) with $\theta_{H}$ implicitly defined by (59) holding as an equality must be continuous and concave in $q_{L}$ and $\theta_{L}$ at the point of optimum. Hence it cannot be optimal for the monopolist to only adjust one margin in response to a change in the relative market size. Then we have both $\partial q_{L} / \partial n_{H}$ and $\partial \theta_{L} / \partial n_{H}$ non-zero throughout and $\partial q_{L} / \partial n_{H}<0$ and $\partial \theta_{L} / \partial n_{H}<0$ hold for all $n_{H}$. The same conclusion on $\partial \theta_{L} / \partial n_{H}<0$ follows since the incentive compatibility constraint holding as an equality defines positive relationships between $q_{L}$ and $\theta_{H}$ and between $\theta_{L}$ and $\theta_{H}$. The decline in job creation in either market lowers employment for both skill types and by (62) also lowers wages.

Proposition 16 In second degree price discrimination with binding incentive compatibility and if $\varepsilon_{\eta}(\theta)$ is constant, an increase in the relative supply of high skill workers raises the skill premium, the relative rate of employment and the ratio of expected earnings for sufficiently small $h_{H} / h_{L}$.

Proof. Combining (59) holding as an equality, (60) and (61) yields $\frac{\eta\left(\theta_{L}\right)}{\eta\left(\theta_{H}\right)} \varepsilon_{\eta}\left(\theta_{L}\right) h_{L}+\left(\frac{\eta\left(\theta_{L}\right)}{\eta\left(\theta_{H}\right)}-1\right)\left(h_{L}-q_{L}^{\gamma-1}\left(1+\varepsilon_{\eta}\left(\theta_{L}\right)\right)\right)-\varepsilon_{\eta}\left(\theta_{L}\right) \gamma q_{L}^{\gamma-1}-h_{H}+h_{L}=0$ 
If $\varepsilon_{\eta}(\theta)$ is constant, this defines $\eta\left(\theta_{L}\right) / \eta\left(\theta_{H}\right)$ as an implicit function of $q_{L}$ only. In particular,

$$
\frac{d\left(\eta\left(\theta_{L}\right) / \eta\left(\theta_{H}\right)\right)}{d q_{L}}=(\gamma-1) q_{L}^{\gamma-1} \frac{\left(\eta\left(\theta_{L}\right) / \eta\left(\theta_{H}\right)-1\right)\left(1+\varepsilon_{\eta}\right)+\varepsilon_{\eta} \gamma}{\left(1+\varepsilon_{\eta}\right)\left(h_{L}-q_{L}^{\gamma-1}\right)}
$$

Since we have $\partial q_{L} / \partial n_{H}<0, d\left(\eta\left(\theta_{L}\right) / \eta\left(\theta_{H}\right)\right) / d n_{H}>0$ if and only if the above is negative. The denominator is positive since $q_{L}<q_{L}^{\prime}$. Then $d\left(\eta\left(\theta_{L}\right) / \eta\left(\theta_{H}\right)\right) / d q_{L}<0$ if the numerator is negative which is the case for $\eta\left(\theta_{L}\right) / \eta\left(\theta_{H}\right)$ sufficiently close to 1. This will be the case if the difference in job creation for the two skill types is small. If the difference in productivity is minimal, the difference in job creation will similarly be minimal. Increases in $\eta\left(\theta_{L}\right) / \eta\left(\theta_{H}\right)$ will raise the wage premium as given by (54). The relative rate of employment as given by (14) likewise increases in response to the increase in $\eta\left(\theta_{L}\right) / \eta\left(\theta_{H}\right)$, as well as the increase in $\eta\left(\theta_{L}\right)$. The same conclusion on the relative rate of employment then follows.

This proposition concludes that as the relative supply of high skill workers increases, the remaining low skill workers can be made relatively worse off. The qualifications required for the proposition to hold are sufficient but not necessary conditions. ${ }^{16}$ The proposition should hold for much weaker conditions. Unfortunately, the algebraic complexity of the solution in second degree price discrimination as given by (59), (60) and (61) precludes the derivation of more general results.

\footnotetext{
${ }^{16}$ Incentive compatibility binds for small $h_{H} / h_{L}$ and hence the qualifications in the proposition cover a non-empty subset of the parameter space.
} 